\title{
Finding the missing millions - the impact of a locally enhanced service for COPD on current and projected rates of diagnosis: a population-based prevalence study using interrupted time series analysis
}

\author{
Christine Falzon', Michael Soljak², Sarah L Elkin³, lain D Blake1, *Nicholas S Hopkinson ${ }^{4}$ \\ ${ }^{1}$ Central London Community Healthcare, 64 Victoria Street, Westminster, London, UK \\ 2 Department of Primary Care and Public Health, Imperial College London, London, UK \\ ${ }^{3}$ Respiratory Medicine, Imperial College NHS Trust, London, UK \\ ${ }^{4}$ NIHR Respiratory Disease Biomedical Research Unit at the Royal Brompton and Harefield NHS Foundation Trust and Imperial College London, \\ London, UK
}

Received 24th August 2012; revised 15th October 2012; accepted 19th October 2012; online 22nd January 2013

\begin{abstract}
Background: Many patients with chronic obstructive pulmonary disease (COPD) are not identified until their condition is relatively advanced and there is a considerable gap between the modelled and diagnosed prevalence of the disease. We have previously shown that, in the first year after the introduction of a locally enhanced service (LES) for COPD in 2008, there was a significant step-up in the diagnosed prevalence.

Aims: To investigate whether this initial increase in prevalence was sustained, and the impact of this increase on future projected rates of COPD diagnosis.

Methods: Using data from 2005-2011, we compared the prevalence of diagnosed COPD in the LES Primary Care Trust (LES-PCT) before and after it was introduced. Data were compared with a neighbouring PCT, the London Strategic Health Authority, and England. The true prevalence of COPD was estimated based on data from the Health Survey for England. Trends were extrapolated to estimate the proportion of patients that would be diagnosed in 2017.

Results: The introduction of the LES was associated with a significant acceleration in the annual increase in diagnosed COPD ( $<<0.0001)$. By 2011 the prevalence was $1.17 \%$ in the LES-PCT compared with a predicted value of $0.91 \%(95 \% \mathrm{Cl} 0.86 \%$ to $0.95 \%)$ based on the pre-LES trend. There was no change in the rate of increase in COPD prevalence for the neighbouring PCT or for London as a whole. The LES-PCT would be expected to diagnose $55.6 \%$ of COPD patients by 2017 compared with only $27.3 \%$ without the LES, and only $33.3 \%$ would be diagnosed in the neighbouring PCT.

Conclusions: These data suggest that, with appropriate incentives, it is possible to achieve a sustained improvement in COPD case-finding in primary care and that such policies need to be implemented systematically.

(C) 2013 Primary Care Respiratory Society UK. All rights reserved.

C Falzon et al. Prim Care Respir J 2013; 22(1): 59-63

http://dx.doi.org/10.4104/pcrj.2013.00008
\end{abstract}

Keywords COPD, spirometry, prevalence, modelling, primary care

See linked editorial by Roberts and Gaduzo on pg 12

\section{Introduction}

Despite being a major cause of morbidity and mortality, predicted to become the third biggest cause of death and the fifth largest contributor to disability-adjusted life years by 2020, chronic obstructive pulmonary disease (COPD) remains significantly underdiagnosed..$^{1,2}$ This means that patients with the condition are being

\footnotetext{
* Corresponding author:Dr N S Hopkinson, Senior Lecturer and Hon Consultant Respiratory Physician, NIHR Respiratory Disease Biomedical Research Unit at the Royal Brompton and Harefield NHS Foundation Trust and Imperial College London, Fulham Road, London SW3 6NP, UK.

Tel: +44 (0)207349 7775 Fax: +44 (0)2073497778 E-mail: n.hopkinson@ic.ac.uk
} 
denied appropriate lifestyle and therapeutic interventions which have the potential to improve health status and survival. ${ }^{3-7}$ Indeed, a significant proportion of patients are not diagnosed until they are admitted to hospital with an acute exacerbation. ${ }^{8}$ Under the UK Quality and Outcomes Framework (QOF), primary care has been incentivised to maintain a register of COPD patients and record inhaler technique, spirometry, and smoking status every 15 months.

A locally enhanced service (LES) for COPD was introduced by Kensington and Chelsea (K\&C) Primary Care Trust (PCT) in 2008. PCTs are local National Health Service (NHS) organisations responsible for commissioning of healthcare services. A key feature of the LES was that it included a small financial incentive for general practitioners (GPs) to perform spirometry, but a larger one where COPD patients were identified and received the additional quality items of care including spirometry and pulse oximetry; a review of smoking with smoking cessation advice and referral to a smoking cessation service if appropriate; recording of body mass index and MRC dyspnoea score; review of inhaler technique; medication review; provision of a COPD rescue pack if appropriate; issuing a self-management plan; and influenza and pneumococcal vaccination. ${ }^{9}$ This encouraged GPs to focus case-finding efforts on those most likely to have the condition. We have previously reported that, in the first year, the LES produced a sharp increase in the diagnosed COPD prevalence, whereas there was no divergence from the slow rate of increase in diagnosed prevalence in either a neighbouring PCT which was part of the same integrated service improvement programme but which had not implemented the LES, or in the London Strategic Health Authority (SHA) area as a whole. ${ }^{9}$ Details of the development of the LES are contained in the online supplement to that publication.

The LES has continued to operate, and the first aim of this study was to investigate whether the initial effect of the LES that we had observed was sustained. As a second objective we wished to investigate the implications of the current rate of increase in prevalence for the proportion of COPD patients who would have been identified 5 years from now in 2017 .

\section{Methods}

Annual QOF report data on diagnosed or GP-registered prevalence of COPD at the PCT level from 2005 through to March 2011 were obtained from the Quality Management and Analysis System (QMAS) database via the NHS Information Centre. The QMAS is a national IT system which gives GP practices and PCTs objective evidence and feedback on the quality of care delivered to patients. It supports the QOF element of the UK GP contract and has been in operation since 2004.

Estimates of the 2011 population prevalence of COPD were calculated using a model developed at the Department of Primary Care and Public Health, Imperial College, London ${ }^{10}$ (available at http://www.apho.org.uk/diseaseprevalencemodels). The model was developed using data from the 2001 Health Survey for England. The model takes into account age, sex, ethnicity, smoking status, rurality, and deprivation score at the GP practice level. The trends in diagnosed COPD prevalence before and after the introduction of

Figure 1. Prevalence of chronic obstructive pulmonary disease (COPD) in Kensington \& Chelsea (K\&C) Primary Care Trust (PCT), Westminster PCT, London Strategic Health Authority (SHA), and England. The diagnosed prevalence of COPD rose at a significantly increased rate $(p<0.0001)$ in K\&C PCT following the introduction of the locally enhanced service for COPD in 2008. Trends in neighbouring Westminster PCT and the London SHA area as well as England as a whole are unchanged. The dotted line represents the K\&C prevalence 2005-2008 extrapolated forward with $95 \% \mathrm{Cl}$ error bars.

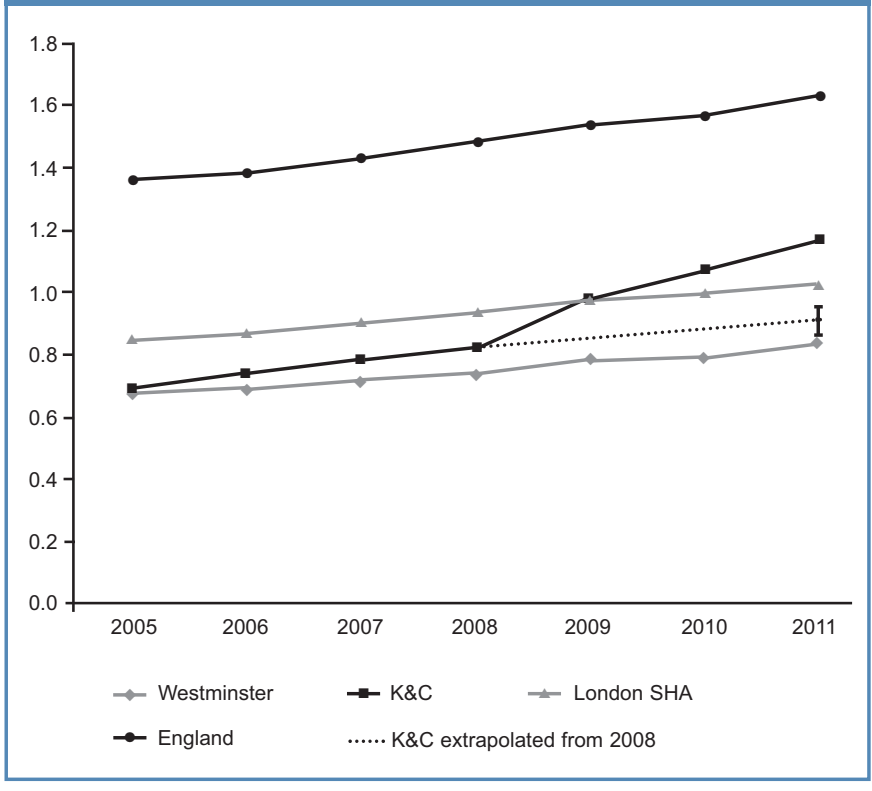

Table 1. Diagnosed prevalence of chronic obstructive pulmonary disease (COPD) for reporting years 2005-2011

\begin{tabular}{|c|c|c|c|c|c|c|c|}
\hline & 2005 & 2006 & 2007 & 2008 & 2009 & 2010 & 2011 \\
\hline Westminster PCT & 0.677 & 0.690 & 0.718 & 0.740 & 0.783 & 0.790 & 0.837 \\
\hline Kensington \& Chelsea PCT & 0.692 & 0.742 & 0.780 & 0.822 & 0.979 & 1.072 & 1.167 \\
\hline London SHA & 0.850 & 0.868 & 0.903 & 0.935 & 0.975 & 0.996 & 1.026 \\
\hline England & 1.358 & 1.376 & 1.427 & 1.481 & 1.535 & 1.563 & 1.625 \\
\hline
\end{tabular}


Table 2. Expected COPD prevalence in 2017

\begin{tabular}{|c|c|c|c|c|}
\hline & Regression equation & $r^{2}$ & $\begin{array}{l}\text { Modelled prevalence } \\
(\%)\end{array}$ & $\begin{array}{l}\text { Estimated diagnosed prevalence } \\
\text { in } 2017, \%(95 \% \mathrm{Cl})\end{array}$ \\
\hline Kensington \& Chelsea PCT & $y=0.1126 x+0.7287$ & 0.98 & 3.33 & 1.85 (1.39 to 2.29$)$ \\
\hline Westminster PCT & $y=0.030 x+0.7123$ & 0.94 & 3.03 & $1.01(0.88$ to 1.24$)$ \\
\hline London SHA & $y=0.0277 x+0.9131$ & 0.99 & 2.96 & $1.19(1.09$ to 1.31$)$ \\
\hline England & $y=0.0461 x+1.4356$ & 0.98 & 2.93 & 1.89 (1.71 to 2.09$)$ \\
\hline
\end{tabular}

the LES were compared using interrupted time series analysis. Extrapolation of a simple linear regression model was used to calculate the expected diagnosed prevalence together with 95\% confidence intervals $(95 \% \mathrm{Cl})$ in the different areas for the year 2017. True COPD prevalence was assumed to remain constant over time and expressed as a proportion of the whole population.

\section{Results}

Table 1 and Figure 1 show that diagnosed COPD prevalence has continued to rise in $\mathrm{K} \& C \mathrm{PCT}$ at a faster rate than in Westminster PCT where the LES is not in place and compared with the London SHA and with England. Using interrupted time series analysis around the introduction of the LES in 2008, there was a significant acceleration in the annual rate of increase in COPD diagnosis in $K \& C(p<0.0001)$ but no significant change in Westminster $(p=0.6)$, London SHA $(p=0.5)$, or England $(p=0.8)$. To quantify the effect of the LES in K\&C, we extrapolated the prevalence data for the four years from 2005 to 2008 before it was introduced. On this basis, the 2011 diagnosed prevalence in $\mathrm{K} \& \mathrm{C}$ would have been $0.91 \%(95 \% \mathrm{Cl} 0.86 \%$ to $0.95 \%$ ) compared with the observed prevalence of $1.17 \%$. For the other populations, the prevalences observed in 2011 all fell within the 95\% Cls based on extrapolating 2005-2008 data which were as follows: Westminster $0.81 \%(95 \% \mathrm{Cl} 0.76 \%$ to $0.85 \%)$; London $1.02 \%$ (95\% Cl $0.95 \%$ to $1.09 \%)$; England 1.6\% (95\% Cl 1.45\% to $1.73 \%)$.

\section{Projected future rates of diagnosis}

Table 2 gives the regression equations and $r^{2}$ values for trends in prevalence using annual data for 2008-2011 as well as Cls for when these would reach the modelled prevalence. For K\&C, London, Westminster and England, respectively, $r^{2}$ values were 0.98, 0.99, 0.94 , and 0.98 , suggesting that a linear model is reasonable. On the basis of the 2008-2011 trends, by 2017 the expected diagnosed prevalences would be: $\mathrm{K} \& \mathrm{C} 1.85 \%(95 \% \mathrm{Cl} 1.39 \%$ to $2.29 \%)$; Westminster $1.01 \%$ (95\% Cl 0.88\% to 1.24\%); London SHA 1.19\% (95\% Cl $1.09 \%$ to $1.31 \%$ ); and England $1.89 \%$ (95\% Cl $1.71 \%$ to $2.09 \%)$. These are $55.6 \%, 33.3 \%, 40 \%$, and $64.5 \%$ of the respective modelled prevalences. Based on the pre-LES trend, the expected prevalence in $\mathrm{K} \& \mathrm{C}$ in 2017 would be only $1.17 \%(95 \% \mathrm{Cl}$ $1.07 \%$ to $1.25 \%$ ), or $27.3 \%$ of the modelled prevalence.

\section{Discussion}

\section{Main findings}

The main finding of this study is that the introduction of the LES for
COPD in Kensington and Chelsea in 2008 was associated with a sustained significant increase in the rate of COPD case-finding rather than a one-off change. By contrast, the rate of change in diagnosed COPD prevalence both in the rest of London and in England as a whole has not changed. Extrapolating a short distance into the future, $55.6 \%$ of COPD patients in K\&C would have been identified by 2017 with the LES in place but only $27.3 \%$ without.

\section{Strengths and limitations of the study}

Since we have not used an experimental design, some caution is needed regarding causality and assuming that the increase in casefinding is due to the LES and not to another factor such as regression to the mean or other interventions. The stability of the trend in prevalence in a neighbouring PCT that was also part of the same integrated service improvement programme for COPD - but where the LES was not introduced - supports our hypothesis that the LES was the cause of the increased identification of patients, as does the stability across the London SHA and England as a whole.

We extrapolated trends in diagnosed COPD a short period into the future to highlight the potential impact of the LES. We have assumed that the actual prevalence of COPD would remain constant at that modelled for 2011. It is likely that demographic changes and changes in smoking habits will influence the true prevalence of COPD, but these differences are likely to be small over the time period involved. Our focus is on what can be done to narrow the gap that exists at the present time between the diagnosed and true prevalence of the disease. The purpose of the extrapolation is to illustrate the potential consequences of failing to address the systemic issues that contribute to under-diagnosis of COPD now.

\section{Interpretation of findings in relation to previously} published work

The key implication of these data is that the net effect of efforts so far to deal with the problem of the 'missing millions' ${ }^{2}$ of patients with as yet undiagnosed COPD are simply inadequate, and that the provision of an appropriate structure of incentives to make casefinding a worthwhile activity for GPs - in this case the LES where reimbursement was tied directly to identifying patients and delivering quality care - appears to be an effective strategy. In particular, the sustained improvement achieved between 2008 and 2011 suggests that the initial step-up in prevalence previously reported ${ }^{9}$ was not a one-off phenomenon.

Various case-finding strategies involving spirometry in primary care have confirmed that targeted approaches to at-risk populations can be effective. ${ }^{11-16}$ COPD patients typically have a history including 
cough, sputum, wheeze, or breathlessness in the context of tobacco exposure. ${ }^{17}$ It should not be difficult to identify patients at risk who would be eligible for screening spirometry to confirm or refute the diagnosis. A recent publication reported that a strategy of performing spirometry in primary care patients with a respiratory infection and a history of smoking identified significant numbers of previously undiagnosed COPD patients. ${ }^{12}$ This is unsurprising and prompts the response that this should be a routine standard of care. Implications for future research, policy and practice Although factors such as the education of healthcare professionals, access to spirometry as well as its interpretation, and public awareness of COPD and the significance of respiratory symptoms have rightly been highlighted, a key issue remains one of political will to create the appropriate structures and individual motivation for health professionals to make the diagnosis and manage the additional workload. The management of COPD, particularly with regard to exacerbations and hospital admission, is becoming a priority $^{18}$ because of the need to reduce healthcare expenditure. However, if efforts are not made to diagnose early disease, patients will be denied appropriate care including early aggressive smoking cessation interventions, pharmacological therapy, and pulmonary rehabilitation that can improve quality of life and potentially prevent future admissions..$^{3.6}$

An additional priority is the growing appreciation that physical inactivity is itself an aetiological factor in the development and progression of COPD, 19-21 with evidence that systemic manifestations such as skeletal muscle impairment are present even in early disease. ${ }^{13,22}$ As well as enhancing smoking cessation, ${ }^{4}$ an earlier diagnosis of COPD could be used to motivate patients to adopt a more active lifestyle to prevent progression of the condition. ${ }^{21}$

Although the data presented here apply to England, they have relevance more widely as the issue of timely COPD identification is an important concern for commissioners of healthcare in other settings, given that the condition is estimated to affect approximately $10 \%$ of people over the age of 40 worldwide. ${ }^{23}$ These data suggest that, without specific incentives to identify patients with COPD, limited progress in addressing the problem will be made. This has to be considered in the context of competing demands on healthcare resources. Although we have not collected costeffectiveness data for the LES, in our original report the cost of screening per new diagnosis of COPD was estimated at $194 .{ }^{9}$ This included an initial $£ 1,000$ start-up payment to practices so may be an overestimate of the ongoing cost. The incremental costeffectiveness ratio of opportunistic case-finding has been estimated as a cost per quality-adjusted life year of only $f 814$, which is much lower than many funded healthcare interventions..$^{24}$ An interesting finding is the disparity between London and the rest of England where the proportion of patients diagnosed with COPD is higher. This may reflect specific issues concerning healthcare provision within London, such as a more mobile and ethnically diverse population.

\section{Conclusions}

The present data show that the introduction of the locally enhanced service in Kensington and Chelsea was associated with a sustained acceleration in COPD case-finding. In contrast to this, the net effect of strategies to address the problem of undiagnosed COPD across England - and particularly in London - is inadequate. Early diagnosis is directly relevant to the provision of sustainable health services as the prevention and avoidance of future healthcare needs is a key element for this. ${ }^{25}$

\section{Handling editor Tjard Schermer and Onno van Schayck} Statistical review Gopal Netuveli

Conflicts of interest The authors declare that they have no conflicts of interest in relation to this article.

Contributorship The LES was developed by CF and IDB. NSH and CF collected and analysed the data. MS provided the modelled COPD prevalences. NSH wrote the first draft with CF and all authors contributed to the final draft and approved the final version. NSH is the guarantor of the paper.

Funding The work in this paper was supported by the NIHR Respiratory Disease Biomedical Research Unit at the Royal Brompton and Harefield NHS Foundation Trust and Imperial College London.

\section{References}

1. Nacul L, Soljak M, Samarasundera E, et al. COPD in England: a comparison of expected, model-based prevalence and observed prevalence from general practice data. J Public Health (Oxf) 2011;33(1):108-16. http://dx.doi.org/10.1093/ pubmed/fdq031

2. British Lung Foundation. Invisible lives. Chronic obstructive pulmonary disease (COPD): finding the missing millions. Available at: www.blf.org.uk/Publication/Detail/Invisible-Lives-report

3. Dodd JW, Hogg L, Nolan J, et al. The COPD Assessment Test (CAT): response to pulmonary rehabilitation. A multicentre, prospective study. Thorax 2011;66(5):4259. http://dx.doi.org/10.1136/thx.2010.156372

4. Parkes G, Greenhalgh T, Griffin M, Dent R. Effect on smoking quit rate of telling patients their lung age: the Step2quit randomised controlled trial. BMJ 2008;336(7644):598-600. http://dx.doi.org/10.1136/bmj.39503.582396.2

5. Celli B, Decramer M, Kesten S, Liu D, Mehra S, Tashkin DP. Mortality in the 4 year trial of tiotropium (UPLIFT) in patients with COPD. Am J Respir Crit Care Med 2009;180(10):948-55. http://dx.doi.org/10.1164/rccm.200906-08760C

6. Anthonisen NR. The effects of a smoking cessation intervention on 14.5-year mortality: a randomized clinical trial. Ann Intern Med 2005;142:233-9.

7. Kelly JL, Bamsey $\mathrm{O}$, Smith $\mathrm{C}$, et al. Health status assessment in routine clinical practice: the Chronic Obstructive Pulmonary Disease Assessment Test score in outpatients. Respiration 2012;84:193-9. http://dx.doi.org/10.1159/000336549

8. Bastin A, Starling L, Ahmed R, et al. High prevalence of undiagnosed and severe chronic obstructive pulmonary disease at first hospital admission with acute exacerbation. Chron Respir Dis 2010;7(2):91-7. http://dx.doi.org/10.1177/ 1479972310364587

9. Falzon C, Elkin SL, Kelly JL, Lynch F, Blake ID, Hopkinson NS. Can financial incentives for improvements in healthcare quality enhance identification of COPD in primary care? Thorax 2011;66(7):630. http://dx.doi.org/10.1136/thx.2010.140913

10. Nacul L, Soljak M, Meade T. Model for estimating the population prevalence of chronic obstructive pulmonary disease: cross sectional data from the Health Survey for England. Population Health Metrics 2007;5(1):8. http://dx.doi.org/ 10.1186/1478-7954-5-8

11. Konstantikaki V, Kostikas K, Minas M, et al. Comparison of a network of primary care physicians and an open spirometry programme for COPD diagnosis. Respir Med 2011;105(2):274-81. http://dx.doi.org/10.1016/j.rmed.2010.06.020

12. Sandelowsky H, Stallberg B, Nager A, Hasselstrom J. The prevalence of undiagnosed chronic obstructive pulmonary disease in a primary care population with respiratory tract infections: a case finding study. BMC Family Pract 2011;12(1):122. http://dx.doi.org/10.1186/1471-2296-12-122

13. Kelly JL, Elkin SL, Fluxman J, Polkey MI, Soljak M, Hopkinson NS. Breathlessness and skeletal muscle weakness in patients undergoing lung health screening in primary care. COPD: Journal of Chronic Obstructive Pulmonary Disease 2013;10(1)online. http://www.ncbi.nlm.nih.gov/pubmed/23272667

14. Stratelis G, Jakobsson P, Molstad S, Zetterstrom O. Early detection of COPD in primary 
care: screening by invitation of smokers aged 40 to 55 years. $\mathrm{Br} J$ Gen Pract 2004;54(500):201-6.

15. Zielinski J, Bednarek M; Know the Age of Your Lung Study Group. Early detection of COPD in a high-risk population using spirometric screening. Chest 2001;119(3):7316. http://dx.doi.org/10.1378/chest.119.3.731

16. van Schayck CP, Loozen JMC, Wagena E, Akkermans RP, Wesseling GJ. Detecting patients at a high risk of developing chronic obstructive pulmonary disease in general practice: cross sectional case finding study. BMJ 2002;324(7350):1370. http://dx.doi.org/10.1136/bmj.324.7350.1370

17. National Clinical Guideline Centre. Chronic obstructive pulmonary disease: management of chronic obstructive pulmonary disease in adults in primary and secondary care. London: National Clinical Guideline Centre, 2010.

18. British Thoracic Society Guideline Development Group. Intermediate care: Hospitalat-Home in chronic obstructive pulmonary disease: British Thoracic Society guideline. Thorax 2007;62(3):200-10. http://dx.doi.org/10.1136/thx.2006.064931

19. Garcia-Aymerich J, Lange $P$, Benet M, Schnohr P, Anto JM. Regular physical activity reduces hospital admission and mortality in chronic obstructive pulmonary disease: a population-based cohort study. Thorax 2006;61(9):772-8. http://dx.doi.org/ 10.1136/thx.2006.060145

20. Garcia-Aymerich J, Lange P, Benet M, Schnohr P, Anto JM. Regular physical activity modifies smoking-related lung function decline and reduces risk of chronic obstructive pulmonary disease: a population-based cohort study. Am J Respir Crit Care Med 2007;175(5):458-63. http://dx.doi.org/10.1164/rccm.200607-8960C

21. Hopkinson NS, Polkey MI. Does physical inactivity cause chronic obstructive pulmonary disease? Clin Sci (Lond) 2010;118(9):565-72.

22. Shrikrishna D, Patel M, Tanner RJ, et al. Quadriceps wasting identified by ultrasound and its association with physical inactivity in mild COPD. Eur Resp J 2012;40(5):1115-1122. http://dx.doi.org/10.1183/09031936.00170111


of COPD (the BOLD Study): a population-based prevalence study. Lancet 2007; 370(9589):741-50. http://dx.doi.org/10.1016/S0140-6736(07)61377-4

24. National Institute for Clinical Excellence. National clinical guideline on management of chronic obstructive pulmonary disease in adults in primary and secondary care. Thorax 2004;59:i1-232.

25. Kmietowicz Z. NHS needs to do more to meet UK targets on greenhouse gases. BMJ 2012;344:e2164. http://dx.doi.org/10.1136/bmj.e2164

Available online at http://www.thepcrj.org 